\title{
The Effects of Patient Empowerment Scale in Chronic Diseases
}

\author{
Michael Galanakis' ${ }^{1}$, Sofia Tsoli ${ }^{2}$, Christina Darviri2 ${ }^{*}$ \\ ${ }^{1}$ Panteion University of Social and Political Sciences, Athens, Greece \\ ${ }^{2}$ Postgraduate Course Science of Stress and Health Promotion, School of Medicine, University of Athens, \\ Athens, Greece \\ Email: *cdarviri@yahoo.com
}

How to cite this paper: Galanakis, M., Tsoli, S., \& Darviri, C. (2016). The Effects of Patient Empowerment Scale in Chronic Diseases. Psychology, 7, 1369-1390. http://dx.doi.org/10.4236/psych.2016.711138

Received: January 5, 2016

Accepted: October 28, 2016

Published: October 31, 2016

Copyright $\odot 2016$ by authors and Scientific Research Publishing Inc. This work is licensed under the Creative Commons Attribution International License (CC BY 4.0).

http://creativecommons.org/licenses/by/4.0/ (c) (i) Open Access

\begin{abstract}
Chronic diseases in patients have always been a significant sector of study by various scientists. Patient's empowerment in situations like these has an enormous importance in order to succeed a better knowledge of how to face these difficulties. The value of empowerment is enormous and has to be the goal of modern research. When it is found in the patient's behavior, we can definitely agree to the fact that he is able to make decisions on his own and to have the total control of his life, along with its problems for example when his health is in danger, or when he faces a sentimental problem. The consequences of stress in our life can be immense and they have a negative effect on the self-confidence of the individuals, as well. The Patient Empowerment Scale (PES) was measured to the patients with chronic diseases through a systematic review. The Patient Empowerment Scale (PES) has been evaluated with the use of Pubmed/Medline. Of the 118 studies included in this review, 44 articles presented inclusion criteria. 27 scales were obtained through open access and they were evaluated through the participation definition. Of the 27 studies included there were 14 studies that measured patient empowerment in chronic diseases, 4 studies showed data for calculation of an SMD for self-efficacy disease-specific outcomes, 2 studies included a measurement of self-esteem, measured with the Rosenberg Selfesteem (RSE) Scale, 4 studies that measured the decision making and there were 3 studies that included the quality of life measurement. The evolution of the patient's health, through self-management, can be improved on increasing his empowerment. It is very important for a clinical to provide his patient with all the necessary material and to give him the possibility of a productive conversation, in order to succeed an increased empowerment on his patient. Future studies will have to broaden their criteria to include different languages, longer time period and larger sample.
\end{abstract}

\section{Keywords}

Patient Empowerment, Chronic Diseases, Empowerment Outcome Measures, 
Quality of Life, Self-Esteem, Decision Making

\section{Introduction}

Globally, health sector is interested in the research and management of chronic diseases and their effects on patients, particularly through empowerment-based self-management interventions (EBSMIs). Health sector seeks answers on how each patient will be able to understand in practice, control and improve his health status, temporarily and chronically through self-empowerment (Bruegel, 1998). An important role in this research interest holds the communities, (non)governmental organizations and the health care system (Harris \& Veinot, 2004). Since four decades ago (Tomes, 2007), patient empowerment is used to explain the cost reduction the communities made on health care due to the increase in health care consumerism (Segal, 1998). Each patient is an active member in his understanding of health organization and protection (Neuhauser, 2003; Jones et al., 2004). Today's researches and organizations which are interested in patients' health are in action, as WHO (World's Health Organization) proves empowerment as the key factor for health care, self-care and quality of life for people with chronic diseases (Aymé et al., 2008). The most recent strategies examined for selfempowerment deal with disease management and the relationship that a patient develops with his health care providers (Aujoulat et al., 2007; Aymé et al., 2008). The main future goal of the studies and the researches is a greater and more accurate evaluation on the patient self-management programs (Anderson et al., 1995; Elzen et al., 2007; Foster et al., 2007; Funnell et al., 2005; Lorig et al., 2001; Tsay et al., 2004; Viklund et al., 2007; Wong et al., 2004) in order for patients to find a way to decide over their treatment (decision making) (Davison \& Degner, 1997; Huby et al., 2007) and to better interact with their physicians (Little et al., 2004; McCann \& Weinman, 1996; Anderson, 2007). A systematic review for patients with chronic diseases has been waged, by measuring the Patient Empowerment Scale (PES). What is missing from all the researches and studies made on patient empowerment and its effects in chronic illnesses, is a systematic review on the evaluation of this system. New researches must be done so that the everyday life of the patients can be improved. There must be found a way that everyday life won't underlie stress and problems for one's self-empowerment, self-esteem, self-efficacy, and valuable decision making.

\section{Methods}

\section{Inclusion Criteria}

Types of Studies

All type of studies randomized controlled trials (RCT) (Sjöblad, 2008), quasi-randomized controlled trials, synchronic studies (Chiu et al., 2010), that were related to patient empowerment and diseases were included. No references to empowerment and related outcomes were excluded or locked unavailable articles, manual papers, book 
chapters, opinion articles and commentary notes.

\section{Types of Participants}

Studies in which the intervention was aimed at humans/patients with a medical problem like cancer, diabetes type 2, fibromyalgia, arthritis-osteoporosis, multiple hardening, asthma (Chibbend et al., 2010; Haywood et al., 2006; Blakeman et al., 2011) were included.

\section{Types of Intervention}

Studies in which the treatment were been made by a Web-based intervention were included. Web-based interventions via electronic discharge notes were considered as all interactive Web applications (Homko et al., 2007). Furthermore, we excluded studies in which the intervention did not mention any aspects of health education and also studies were conducted before 2005 .

\section{Types of Outcome Measures}

Studies that measured empowerment or empowerment-related concepts were included. Examples of these are self-efficacy, self-esteem, decision making and quality of life (Hansson \& Bjorkman, 2005; Palloni et al., 2007; Machin et al., 2011; Lehman, 1983). There was also a restriction of language. Articles that were not presented in English, excluded.

\section{Data Collection of the Articles}

\section{Search Strategy}

Publications were tested by a search of the following electronic database:

Pubmed/MEDLINE (2005-2016)

Briefly, we composed two search concepts. The first was about the concept of empowerment and the second one the concept of synonyms were used to such as self-esteem, self-efficacy, decision making and quality of life.

Pubmed/Medline, one of the most content valid, reliable and theoretically enriched journal database, consisted the main research tool of the latest reviews on Patient Empowerment Scale (PES) analysis. This database offered information from 2005 up to today, including 118 studies and free full texts about researches on human species and mixed studies, all presented in English. Of the 118 studies, 74 did not meet the inclusion criteria (Sjoblade et al. 2008) (Chibbend et al. 2010; Haywood et al., 2006; Blakeman et al., 2011; Homko et al., 2007; Hansson \& Bjorkman, 2005; Palloni et al., 2007; Machin et al., 2011). Of the 74 studies the 30 articles did not included all the criteria of our study, specifically, there was not a clearly specification according to chronic diseases and patient empowerment. Mainly, on how patient empowerment had a positive impact on Chronic metabolic diseases, arthritis, diabetes, cancer, stress and mental diseases, cardiovascular diseases, low-back pain, rheumatic disease and fibromyalgia (Anderson \& Funnell, 2010; Wandwalo et al., 2006; Watt et al., 2010). The rest 44 articles included the criteria that we mentioned (Table 1), but 17 of them were unavailable to access/locked. The total number of studies was 27 . These 27 articles were classified in 14 studies according to empowerment (Wahlin, 2006), in 4 studies according to self-efficacy (Lorig et al., 2006), in 2 studies according to self-esteem (Hansson \& 
Bjorkman, 2005), in 4studies according to decision making (Machin et al., 2011) and in 3 studies according to quality of life (Lehman, 1983).

\section{Results/Measurements}

\subsection{Types of Outcome Measures}

Empowerment cannot be studied, measured and evaluated as a general concept. For this reason, systematic researches have been focused on spherical concepts through which empowerment can be examined. Such concepts include "self-efficiency, selfesteem, perceived control, quality of life and decision-making (Figure 1) (Zimmerman, 1995)".

\subsection{Empowerment}

Empowerment was measured with the Diabetes Empowerment Scale (DES) (14 studies).

Table 1. Eligibility criteria for articles.

\begin{tabular}{ll}
\hline \multicolumn{1}{c}{ Inclusion criteria } & \multicolumn{1}{c}{ Exclusion criteria } \\
\hline $\begin{array}{ll}\text { 1) All type of studies that clearly specified chronic diseases } \\
\text { relative to patient empowerment }\end{array}$ & $\begin{array}{l}\text { 1) Locked or unavailable articles } \\
\text { 2) Studies conducted in human }\end{array}$ \\
$\begin{array}{ll}\text { 3) Mixed methods (Web-based methods/e-Health records) } \\
\text { or commentary notes }\end{array}$ & $\begin{array}{l}\text { 3) Before 2005/No related to health education } \\
\text { 4) Full text articles studied in English }\end{array}$ \\
$\begin{array}{ll}\text { 5) All types of empowerment (self-esteem, self-efficacy, } & \text { 5o references to empowerment and related } \\
\text { decision making, quality of life) } & \text { 5) Articles not presented in English }\end{array}$
\end{tabular}

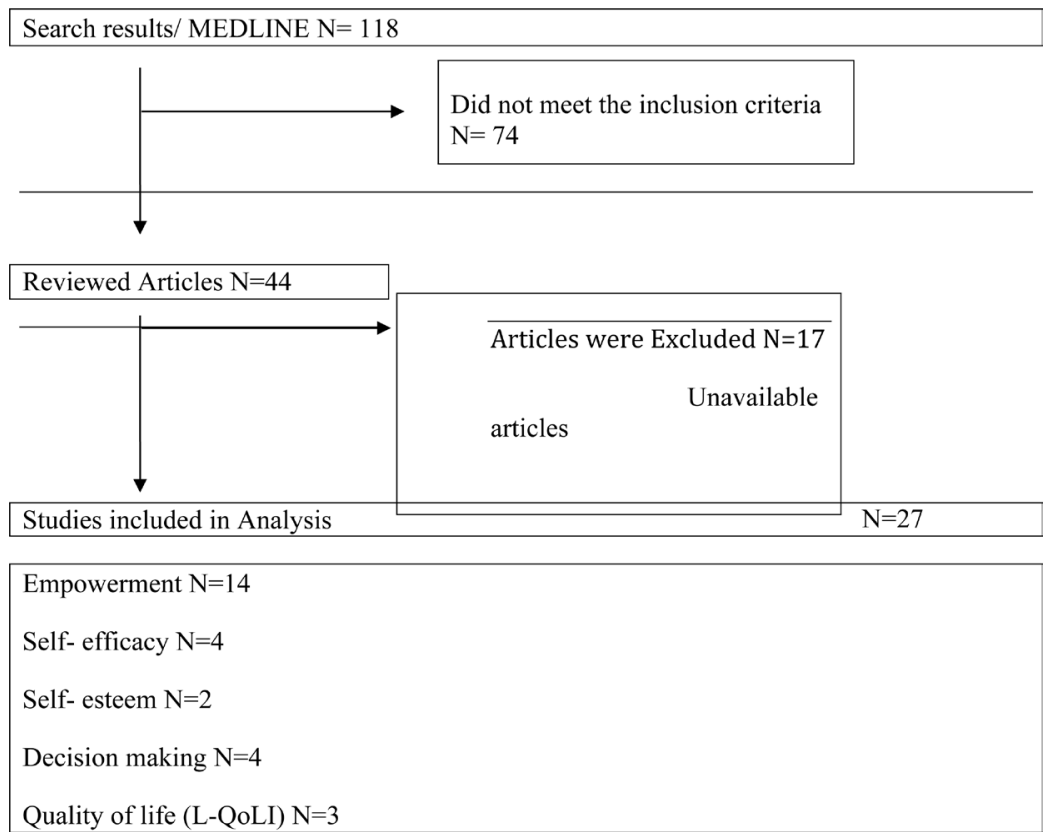

Figure 1. Screening progress of selected articles. 
The Patient Perceptions of Empowerment Scale (PPES) (Lewin \& Piper, 2007), includes the measurement of self-care, self-monitoring (locus of control), self-governing, selfperception and the sources of knowledge and attendance. The diabetes of type 2 constitutes a metabolic disease that relates with increased level of cortisol in the blood and with chronic stress (Cooper et al., 2003). The Diabetes Empowerment Scale (DES) was measured in order to show the empowerment perception's patients who suffered from the metabolic disease, diabetes type 2, had for their treatment (Anderson \& Funnell, 2010). Constant long-lasting self-care, self-governing, self-monitoring knowledge, control and attendance were the fundamental items being measured. When the Patient Empowerment was highly presented, patient's health seemed to improve and get an active attendance in their self-care (Delavari \& Mahdavihazaveh, 2005). In other study an innovator approach was developed in order to recognize when the patients have selfcontrol and when they are in charge of the daily self-governing of their diabetes (Coons et al., 1989). This approach was based on the significance of empowerment, where self-control and self-governing were the two key items being measured in order to evaluate the empowerment of the diabetic patients. The four fundamental empowerment factors, chronic care of disease, choices, control and consequences, revealed that socially wired and self-regulated patients with will to change the way they were living adapting a healthy life attitude, had presented optimistic results (Funnell \& Anderson, 2010). One synchronic study was conducted on 688 diabetics, using as tool of measurement the Diabetes Empowerment Scale (Liu et al., 2010) measuring the way diabetics were mentally understanding their disease, how and in what aspects the disease constituted a negative impact on their lives and how determined and ready they were to achieve a fundamental life change. The measure included: 1) the psychological aspect of diabetes, 2) the speculated dissatisfaction of patient, 3) the willingness of the patient for change and 4) determination and the achievement of goals. The statistic results showed that age and willingness along with dissatisfaction and willingness (Alhani, 2002), both had a positive correlation for the change and duration of this disease. Minet and his affiliates also examined in a study the levels of Patient Empowerment. The experimental results presented a drop on the "dissatisfaction and willingness for change" as the empowerment levels increased (Minet et al., 2010), and they highlighted as the key factor of the Diabetic Patients' Empowerment, the determination and the accomplishment of life changing goals. Homko, examined the effectiveness of an Internet-online based medicine and non medicine treatment that promoted self-management to women with diabetes mellitus (Homko et al., 2007). Through this program women improved their briefing levels of the disease, the entanglement and the influence the practice for their health and in a second level, their self-effectiveness, their self-respect and the reduction of pathogenic stress (distress) (Aujoulat et al., 2007; Heinrich et al., 2010; Anderson, 2007; Anderson \& Funnell, 2010). Another study report was conducted, using a sample of 160 Iranian diabetics. The measurement tool used here was the "Diabetes Empowerment Scale" (DES-LF) (Esteghamati et al., 2008), in order to measure the levels of empowerment these patients possessed. As the results presented, the most important 
factor responsible for the empowerment levels was "the control-management of psychological aspects of diabetics" and as the Cronbach a (the lower bound estimate of the reliability of the psychometric test) revealed there was a strong correlation "between 0.941 until 0.968 and statistical importance $(r=0.75, p<0.001)$ (WHO Study Group, 1985; SWEDIABKIDS, 2011). In Sweden, a frequent phenomenon is the continuous infusion of insulin (CSII) in children with diabetes (Sjöblad, 2008). However, evaluation researches on the glycemic control with CSII use present doubtful results (Segal, 1998). The sugar juvenile diabetes of type 1 have autoimmune and genetic duality, and they are insulin-dependent" (International Diabetes Federation, 2011). Though, even with continuous infusion of insulin (CSII), some children don't accomplish satisfactory glycemic control. In order to find the parents involvement, the degree of support the children get and the control of diabetes during adolescent both from the parent and the child himself, one relative study of self-regulation was conducted. The tool that was used for this study was a personal-centered empowerment scale, "named Self-Determination Young" (Zoffmann and Kirkevold, 2012) (GSD-Y). This scale firstly, helped the diabetic patient to deal with methodological problems of insulin regulation and secondly, worked as a guide for the patient on how to become independent and develop manual skills (self-sufficient and the development of dexterities) in order to face diabetes (Husted et al., 2011). The results of this study report can be summarized into three main accomplishments. GSD-Y tool resolved the once dynamic conflicts between parent and child, increased self-regulated health control and improved the metabolic regulations of the children patients (Roberts, 1999). The outcome of these three accomplishments fixed empowerment as a self-regulatory factor with a certain health care control, based on certain health management and care, different on each individual, rather than one passive receptor of health care (Gibson, 1991), This has impact in the conformity of the patient and in the engagement with the indications of the health professor along with the patient's entanglement in the decision-making with regard to treatment (Gibson, 1995; Howie et al., 1997). In a recent study the scale of "Patient Enablement Instrument" (PEI) (Wahlin, 2006) was used to measure the capacity of a patient to comprehend and to cope with his chronic low back pain condition, after his appointment with the doctor. The main tool of this study report was the scale "Patient Enablement Instrument" (PEI) (Wahlin, 2006). The questionnaire included "6 scale elements three points of scale ('similar or less' to 'much better') and with a choice of a non-applicable answer". The illness examined here was a patient's chronic low back pain and the tool scale measured in what extent the patient self-empowerment was high and he faced life optimistically with confidence to keep himself healthy. The higher levels of PEI showed higher levels of patient empowerment. As the results proved, the most important factor for the patient empowerment was his relationship with his health therapist and how the professor helped the patient to become self-sufficient and autonomous (Glaser, 1978). The relationship between patient and professor was positively affected from their communication which was proved to be therapeutic for the patient (Miles \& Huberman, 2014). The empowerment levels for each patient depend 
strongly on his culture, his age and his socio-economic status. In a research, patient with pulmonary disease being empowered by the health professors through education, advisory, patient centered treatment and the use of Community support (Henwood \& Pidgeon, 1992; Fayers \& Machin, 2007). The tool that has been used was called PROMS (Ader, 2007), which examined the cognitive control (sense of perception of a condition, why it happened and how it can be helped-supported), the control of decisions (when somebody have the choice to control a condition-to be informed), the behavioristic control (reduction of damage, improvement of life, reduction of factors of danger), the sentimental regulation (effective management and adaptation), the hope on the future (for the self, for their important other one) and the General Practice Patient Survey (GPPS) (Campbell, 2009). GPPS, “General Practice Patient Survey (GPPS) (Campbell, 2009)" it's a survey which included two types of measurement questions. The first type of measurement questions had to do with progressive care answering to questions such: "Is there often only one doctor in General Practices of surgery/heath?" "How often do you usually visit the General Practices?". The second type included measurement questions about general practices of dependence and individuals' care. The results of their respondence showed that when the professor-therapist was communicating and informing his patients for their situation and progression, they presented higher levels of empowerment and health improvement (Hibbard et al., 2010; Haywood et al., 2006; Blakeman et al., 2011). A good sample of what questions the part one of the survey included is the following: "When do you saw at last the GP in your general check-up? Did you trust that doctor?" "Did he give you enough time?", "Did he explain to you the symptoms?", "Did he involve you in the decisions?", "Did he give you the proper attention?" Another synchronic study used five fact dimensions (self-control, identity, selfdecision making, knowledge and comprehension and the capacity for the reception of initiatives) (Hibbard et al., 2010; Haywood et al., 2006; Blakeman et al., 2011), in order to study the levels of empowerment on a sample of 1097 elders patients who faced different types of diseases "(Bulsara et al., 2006) diabetes, coronary disease, intestinal problems, syndrome of chronic lassitude, fibromyalgia, arthritis-osteoporosis, cardiovascular, stress, depression, multiple hardening and asthma”. Almost half patients were diagnosed with articulation pains, diabetes of 2 type and cardiovascular diseases. As a result, the high levels of positive attitude towards the disease, the sense of control, the knowledge-briefing and confidence in the decision-making, were positively related with more intensification and better results for the disease (Klima et al., 2007). The tool scale used in here was the "Patient Assessment of Chronic disease care" (PACIC) (Glasgow et al., 2005). The patients' empowerment helped them to face their personal illness and exclude stress. The scale presented 20 elements in five points of gradation from never to always and measured the Venice domination of a patient, the planning, the resolution of the problems and the continuous support. The empowerment of patients who suffer from a chronic disease, is one of vital importance for them, since it helps them to direct and face their disease, reducing at the same time the negative dimension of their stress (distress) (Hansson \& Bjorkman, 2005). The feeling of control 
can contribute not only in the entanglement of patients for the management of their disease, but it can also help for decision-making, with the concern of treatment choices (Department of Health, 2004). The quantification level of empowerment is considered important, since it constitutes the objective indicator of capacity level of a patient's confrontation, self-effectiveness, and decision-making for the support strategies (Beatty \& Willis, 2007). In a study on old patients who suffered from cardiovascular disease, intensification and satisfaction were measured based on the following scales: Intensification was measured with "Decision Empowerment Scale" (Hansson \& Bjorkman, 2005) which was constituted by 28 self-referent questionnaires drawn in order to measure the intensification in patients with psychological disturbances. It includes 5 sub-scales (self-efficient, force, community activism, conscionable anger and optimism for the future). The satisfaction was measured with the Patient Satisfaction Questionnaire (Ferketich, 1991; Uner \& Turan, 2010) (PSQ), which includes the measurement of hospital care quality during and after treatment. The final PSQ included 11 - 55 questions. The higher the level of the results, the higher the level of satisfaction. When a patient was communicating on a constant base with his therapist and was informed gradually for his situation and improvement, his health seemed to improve. The internal constitution rates that is larger than 80 or 0.90 is considered these with the larger rate of satisfaction and the Sufficiency of Patient Education Questionnaire (Johansson et al., 2003) (SPEQ) was used to measure the education adequacy of patient and is related to information which has received the patient during the hospitalization. The SPEQ includes 8 items of Likert scale with range from 8 - 40, with the lower score indicates the least adequacy of patients information during the hospitalization. The results show that Decision Empowerment Scale $(r=0.69)$ and Patient Satisfaction Scale had a statistic significant importance $(r=0.70)$ and good internal consistency a $>0.8$ between patients who empowered themselves and manage their health problems (Small et al., 2013).

\subsection{Self-Efficacy}

Based on 4 of the 27 included studies and previous related researches that calculated an SMD (standardized mean difference) for self-efficacy and how it affects chronic diseases and other key factors of empowerment, self-efficacy was proven to be both component and a result of patient empowerment. There was examined a positive correlation between empowerment and self-effectiveness which was measured through the selfefficacy scale (Lorig et al., 2001), "a Long-Term Conditions scale which includes 6 measurable elements in 10 points of scale (by 'no means certain' to 'absolutely certain')", or through the "General Self Efficacy Scale (Palloni et al., 2007) which reports the capacity of people to manage suitably the stress factors" for patients with rheumatoid arthritis. "The 'General Self Efficacy Scale' is constituted by 10 elements with 10 points of scale report of Likert, with increased internal cohesion 0.87 . Construct validity was supported by significant Pearson correlations between the HES total scores and the SRDES $(r=0.69)$, GSES $(r=0.77)$ and MDES $(r=0.70)$ ". According to the result, there 
is a strong correlation between empowerment and self-efficacy, supported by previous researches. This shows that self-efficacy is a component and a result of empowerment, as well (Andrew \& Peterson, 2014). Another important factor in a study of self-efficacy is patient's illness confrontation with the combination of his self-effectiveness (Lorig et al., 2006). In the strategies of confrontation and self-effectiveness we can also apply this specific scale, but only when the patients succeed both of them are strengthened. This is due to the fact that the patient may feel that he faces the condition but his control regarding the treatment and its side effects, is actually low. A scale such the "General Self Efficacy Scale" can provide relevant results for the relationship between confrontation and self-effectiveness. Only when the patient deeply understands how self-effectiveness and by excluding side effects, he can present illness confrontation and achieve high levels of empowerment and hence positive impacts over his treatment (Martin et al., 2013). In another study about self-efficacy and women management of chronic diseases (women dealt with management of heart-lung disease and type 2 diabetes $(\mathrm{P}=0.06)$ (Lorig et al., 2008), arthritis or fibromyalgia $(P=0.01)$, and back pain $(P=0.02)$ (Lorig et al., 2002; Man et al., 2006)), an online empowerment program seemed to increase self-efficacy and cause faster patient treatment along with the standardized control care. The same results were found by Man (Man et al., 2006) for patients with brain injury (ABI). In 8 weeks self-efficacy increased more to those who used tele-analogy-basedproblem-solving-program rather than the standardized control problem-solving program.

Last but not least, Zutz created an interactive website for patients with cardiac rehabilitation. The results showed that there was a higher level of exercise-specific selfefficacy after use of an interactive website compared with the control group (Zutz et al., 2007).

\subsection{Self-Esteem}

Self-esteem is another key determiner factor of empowerment. There were conducted two studies which measured patients' self-esteem with the usage of Rosenberg Selfesteem (RSE) Scale (Hansson \& Bjorkman, 2005). The first study review was made by Gollings who tested the empowerment levels in women with eating disorders. This study lasted for 8 weeks and it separated the participants into two groups: the control group and the participation group which was on a constant communication with its clinical therapist (either face to face communication or online communication). The techniques the therapist used were based on self-evaluation, control of social pressures and problem solving about weight, shape and eating issues. Based on the results selfesteem increased more on the participant group rather than on the control group, but there were no significant differences between online empowerment and face-to-face empowerment, “ $(\mathrm{MD}=-0.10,95 \% \mathrm{CI}-0.45$ to 0.25$)$ (Gollings et al., 2010)". The second study review followed the same strategic techniques now tested on patients who suffered from schizophrenia. This time there were used subscales of "Empowerment Scale-J (Segal et al., 1995) and correlation comparisons were made between: self-esteem 
and optimism $(\mathrm{r}=0.853, \mathrm{P}<0.01)$, activism and power $(\mathrm{r}=0.343, \mathrm{P}<0.01)$ power and righteous anger $(r=0.454, \mathrm{P}<0.01)$. The results showed that when patients presented high levels of optimism and self-esteem, their levels of righteous anger were lowered, showing a strong negative correlation between self-esteem and optimism with righteous anger $(\mathrm{r}=-0.508, \mathrm{r}=-0.498, \mathrm{P}<0.01)$. Self-esteem and optimism increased on a parallel line with social adjustment $(\mathrm{r}=0.671, \mathrm{r}=0.665, \mathrm{P}<0.01)$, but in overall this didn't cause any significant increase of the total score of the empowerment Scale-J ( $r=$ 0.052 , n.s.). Finally, when the patients showed an increased degree of social adjustment their levels of righteous anger and power proved to be lowered $(r=-0.268, r=-0.886$, $\mathrm{P}<0.01$ ) (Sumie \& Kunifumi, 2007). Support and increase of Self-esteem along with high levels of optimism and social adjustment helped to a decrease of righteous anger but it didn't present a significant empowerment increase for patients with schizophrenia, after all.

\subsection{Decision Making}

One of the four studies accomplished for decision making measurements had to deal with patients who suffered from psychological disorders and patients with diabetes and chronic kidney disease. To these patients a 28 -item self-report questionnaire was given in order to measure their empowerment. The review included five subscales tested on a four-point scale. The five subscales included power, self-efficacy, righteous anger, community activism and optimism over the future. All of these subscales were tested on how they had been affected by patients' decision making over their own treatment. The results showed a satisfying "internal consistency (Cronbach's alpha $=0.81)$ ". The same strategy with the same "Decisions Empowerment Scale" (Machin et al., 2011) was used for the patients with diabetes and chronic kidney disease. The main goal was to compare and evaluate the differences on decision making (SDM) and treatment satisfaction (TS) between hemodialysis (HD) and peritoneal dialysis (PD) patients. This time the study focused on the dialysis which lasted from 6 to 24 months for all 780 Germans who were surveyed (CORETH-project). The items had been tested regarding shared decision making (SDM), the reason of the way choice and treatment satisfaction (TS). The methodology and the results were the following: "Data were compared regarding to comorbidity, age, education, and employment status-matched groups ( $\mathrm{n}=482)$. HD patients were more negatively in all aspects of SDM than PD patients were (total score: $\mathrm{MPD}=84.6, \mathrm{SD}=24.1$ vs. $\mathrm{MHD}=61.9, \mathrm{SD}=37.3 ; \mathrm{p} \leq 0.0001$ ) (Lorig, 2011). The most important difference was on the item 'announcement of a necessary decision' (delta = 1.3 points on a 6-point Likert-scale). HD patients had a torque to medical decisions (23\%) or medical support (20\%). We also found positive correlations between SDM and TS $(0.16 \leq \mathrm{r} \leq 0.48 ; \mathrm{p} \leq 0.0001)$. In contrast to Decision Making Empowerment Scale (DES-SF), in elders with diabetes, Health Empowerment Scale (HES) Cronbach's alpha was good (0.89)". Other study measured children's decision making in chronic

illnesses such as diabetes type 1, cystic fibrosis and asthma. Children's decision-making involvement (DMI) is one of the most important transitional levels to greater indepen- 
dence (Liprie, 1993). DMI can offer to children information, express of opinion, suggest ideas, share of information, choose threw options provided by parents, or conversations with parents. The analysis consisted of 226 participants. 94\% $(n=213)$ of parents answered "yes" to one of the following items: "My child made a decision", "I made a decision", and "We made a decision together", suggesting that, as expected, there was a decision involved in the majority of discussions (Miller et al., 2008). The results showed that children with high scores in DMI can manage their life properly compared to children with low scores. Furthermore, no differences were founded between the three illness groups on the DMIS subscales, for parent or child assessments (Gregorich,

2006). Parents of male children showed higher levels of parental expression compared to parents of female children $[t(214)=2.23, p<0.03]$. Last but not least, male children had lower levels of child express compared to female children $[t(224)=-2.84, p=$ 0.005]. In other study was measured the perceived involvement in decision making among Chinese patients with chronic hepatitis. 178 patients with chronic hepatitis in the study generally preferred a collaborative role (45\%) or passive role (44\%); only $11 \%$ of patients chose an active role in the treatment of decision making. There was no correct match between patients' perceived and preferred role (Bowker's $\mathrm{S}=33.8, \mathrm{P}<$ 0.001). Also, high levels of decision making were correlated with the age and the education level: Younger and more educated patients were up to have more active roles. At last, a total of $54 \%$ of patients was fulfilled with the decisions of the treatment, whereas $39 \%$ of patients were satisfied with the information care (Zhanq et al., 2011).

\subsection{Lehman's Quality of Life Interview (L-QoLI)}

Lehman's quality of life interview (L-QoLI), was analyzed through three chosen quality of life measurements out of 27 conducted studies. He created a questionnaire (The L-QoLI), with subjective questions, which scaled the social dimension of quality of life in patients with psychiatric issues (Lehman, 1983). The final questionnaire included 26 items analyzing the subjective dimension, distributed in 9 subscales. These items included: "General quality of life, Leisure, Living situation, Family Relations, Finances, Work, Social Relations, Safety, and Health". The questionnaire also analyzed the objective dimension "Family Contacts, Leisure, Social Contacts and Finances) (Auquier et al., 2013)", described in 4 subscales. There was also conducted a study based on an article about the mental disease of schizophrenia. A number of 1.827 people who had been diagnosed with schizophrenia, suffered also from manio-depression, $22 \%$ of whom suffered from major depression and 18\% from bipolar disturbance. The items being measured included: the choices these people had in their life (measured with the "Personal Empowerment Scale"); the perception patients had for the recovery of their mental disease by maintaining control over their lives, (measured with "the Recovery Assessment Scale (Segal et al., 1995))"; life quality (measured by the "Lehman Quality of Life scale (Corrigan, 1999))"; the hope levels (measured with "Herth Hope Index scale (Lehman, 1988))"; the social acceptance (measured by the respective scale) and the levels of depression measured with the "HCL questionnaire (Campbell \& Schraiber, 
1989)". The results were of now surprise. Low levels of empowerment caused "low scores of self-value, social isolation, expression of anger" and vice versa. On the other hand, high levels of empowerment caused high scores of "hope $(r=67)$, the feeling of recovery $(r=67)$ and life satisfaction $(r=47)$ ". Other study estimated the quality of life in patients with chronic obstructive pulmonary disease (Rabe et al., 2007). It was estimated the effectiveness of a health-care strategy in order to improve the patient's clinical control and the quality-of their-life (QoL). The random sample included a total of 801 patients ( $\geq 40$ years of age), registered as having COPD. The program contained Clinical Practice Guidelines (CPG), Educational interventions such as positive motivational feedback, anti-smoking advices, information on nutrition and physical exercise, conformity with the therapeutic treatment, and confirmation of the proper aspirator technique. The results showed that the execution of learning programs produced an increase in the QoL and a decrease in the disease aggravation, compared to standard clinical practice (Naberan et al., 2006). Moreover, outcomes showed that non-pharmacological treatment, such as exercise and relaxation techniques, can be useful in improving the physical tolerance of the patients, especially to those who suffered from dyspnoea which is a symptom that affects mostly the QoL of the patient (Miravittles $M$ et al., 2007). In patients with Thyroid diseases the quality of life is being disturbed (Mishra et al., 2013). A recent study estimated the dimensionality of the Thy PRO scales in a sample of 907 thyroid patients (Watt et al., 2010). Statistical analysis showed that thyroid and specificly the y per thyroid symptoms were positive correlated with tiredness $(\mathrm{CFI}=1.0$, RMSEA $(90 \% \mathrm{CI})=0.02(0.00-$ $0.04)$ ), anxiety $(\mathrm{CFI}=1.0$, RMSEA $(90 \% \mathrm{CI})=0.07(0.04-0.10))$, depressivity $(\mathrm{CFI}=$ 1.0 RMSEA $(90 \% \mathrm{CI})=0.00(0.00-0.00))$ and impaired social and daily life $(\mathrm{CFI}=$ 1.0 , RMSEA $(90 \% \mathrm{CI})=0.08(0.07-0.10)), \mathrm{CFI}=1.0$ RMSEA $(90 \% \mathrm{CI})=0.00(0.00-$ 0.00) (Reeve et al., 2007) (see Figure 2).

\section{Discussion}

Through extensive literature review, we observed that "empowerment" as a measuring tool is used at enough chronic diseases such as Diabetes 1 and 2, chronic inflammatory diseases (CIDs), rheumatoid arthritis, coronary heart disease, cardiovascular problems, asthma, low back pain, metabolic syndrome, thyroid diseases, cancer, kidney diseases, chronic hepatitis, psychiatric and mental diseases such as schizophrenia, manic depression and bipolar disorder. With this systematic review we intended to gain more insight into the effectiveness of the patient's empowerment according to chronic diseases and the empowerment-related outcomes. 14 studies measured Patient Empowerment in Chronic diseases. Statistical correlations within these comparisons showed that Patient Empowerment have a statistically significant positive effect on Diabetes disease measured with the DES. According to a scientific study the diabetics played an active role in the process of their treatment (Anderson \& Funnell, 2010). The results showed that when the Patient Empowerment was highly presented, patient's health seemed to improve and get an active attendance in their self-care, a better self-governing of their 


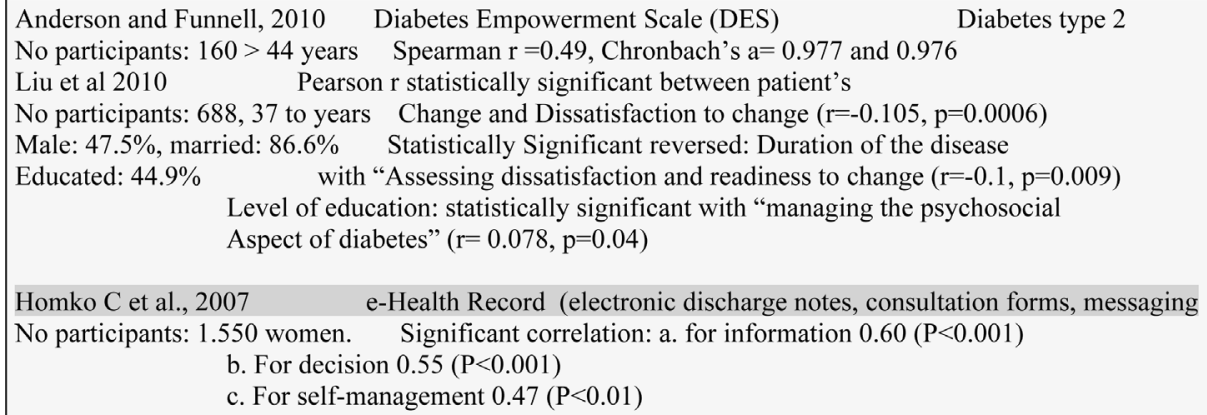

Figure 2. Indicative information.

health and a higher personal control (Delavari \& Mahdavihazaveh, 2005). The statistic results of a synchronic study 688 diabetics using as tool of measurement the Diabetes Empowerment Scale (Liu et al., 2010) showed that age and willingness along with dissatisfaction and willingness (Alhani, 2002), both had a positive correlation for the change and duration of this disease Minet and his affiliates also examined in a study the levels of patient empowerment. The experimental results presented a drop on the "dissatisfaction and willingness for change" as the empowerment levels increased (Minet et al. 2010), and they highlighted as the key factor of the Diabetic Patients' Empowerment, 
the determination and the accomplishment of life changing goals. In another study report of Iranian diabetic population, the levels of empowerment of 160 diabetics were measured using the "Diabetes Empowerment Scale" (DES-LF) (Esteghamati et al., 2008). As the results presented, the most important factor responsible for the empowerment levels was "the control-management of psychological aspects of diabetics" and as the Cronbach a (the lower bound estimate of the reliability of the psychometric test) revealed there was a strong correlation between 0.941 until 0.968 and statistical importance $(\mathrm{r}=0.75, \mathrm{p}<0.001)$ (WHO Study Group, 1985; SWEDIABKIDS, 2011). There were 4 studies showed data for calculation of an SMD for self-efficacy disease-specific outcomes. In a study on old patients who suffer from Rheumatoid arthritis the selfeffectiveness was measured with the "General Self Efficacy Scale (Palloni et al. 2007)". According to the result, there is a strong correlation between empowerment and selfefficacy, supported by previous researches. This shows that self-efficacy is a component and a result of empowerment, as well (Andrew \& Peterson, 2014). Man (Man et al., 2006), showed in a study that people with acquired brain injury (ABI) who followed a tele-analogy-based problem-solving program, after 8 weeks, was founded that selfefficacy levels increased more to those using the program related to the controls. Moreover, Zutz created an interactive website for patients with cardiac rehabilitation. The results showed that there was a higher level of exercise-specific self-efficacy after use of an interactive website compared with the control group (Zutz et al., 2007). There were conducted two studies which measured patients' self-esteem with the usage of Rosenberg Self-esteem (RSE) Scale (Hansson \& Bjorkman, 2005). Significant correlations were found between self-esteem and optimism $(r=0.853, \mathrm{P}<0.01)$, between activism and power $(\mathrm{r}=0.343, \mathrm{P}<0.01)$, and between power and righteous anger $(\mathrm{r}=0.454, \mathrm{P}<$ 0.01 ) in people with schizophrenia Also the results showed that when patients presented high levels of optimism and self-esteem, their levels of righteous anger were lowered, showing a strong negative correlation between self-esteem and optimism with righteous anger $(r=-0.508, r=-0.498, P<0.01)$. Self-esteem and optimism increased on a parallel line with social adjustment $(\mathrm{r}=0.671, \mathrm{r}=0.665, \mathrm{P}<0.01)$, but in overall this didn't cause any significant increase of the total score of the empowerment Scale-J $(r=$ 0.052 , n.s.). Finally, when the patients showed an increased degree of social adjustment their levels of righteous anger and power proved to be lowered $(r=-0.268, r=-0.886$, $\mathrm{P}<0.01$ ) (Sumie \& Kunifumi, 2007). One of the four studies accomplished for decision making measurements had to deal with patients who suffered from psychological disorders and patients with diabetes and chronic kidney disease. In patients with psychological disorders, decision making was measured with Decisions Empowerment Scale (Machin et al., 2011). The results showed that HD patients were more negatively in all aspects of SDM than PD patients were (total score: $\mathrm{MPD}=84.6, \mathrm{SD}=24.1$ vs. $\mathrm{MHD}=$ 61.9, $\mathrm{SD}=37.3 ; \mathrm{p} \leq 0.0001$ ) (Lorig, 2011). Other study measured children's decision making in chronic illnesses such as diabetes type 1, cystic fibrosis and asthma. The results showed that children with high scores in DMI can manage their life properly compared to children with low scores. Last but not least, there were 3 studies that included the quality of life measurement. In the study 1.827 individuals participated and 
had been diagnosed with schizophrenia, manio-depression, $22 \%$ of whom suffered from major depression and 18\% from bipolar disturbance. The empowerment was measured with the Personal Empowerment Scale which measures the degree of the choices that have the individuals in their life. The results showed that low levels of empowerment caused "low scores of self-value, social isolation, expression of anger" and vice versa. On the other hand, high levels of empowerment caused high scores of "hope $(r=67)$, the feeling of recovery $(r=67)$ and life satisfaction $(r=47)$ ". Other study estimated the quality of life in patients with chronic obstructive pulmonary disease (Rabe et al., 2007). In a program that estimated the quality of life in patients with chronic pulmonary disease outcomes showed that non-pharmacological treatment, such as exercise and relaxation techniques, can be useful in improving the physical tolerance of the patients. Finally, in patients with Thyroid diseases the quality of life is being disturbed (Mishra et al., 2013). Statistical analysis showed that thyroid and specifically the hyperthyroid symptoms were positive correlated with tiredness (CFI $=1.0$, RMSEA $(90 \% \mathrm{CI})=0.02(0.00-0.04))$, anxiety $(\mathrm{CFI}=1.0, \mathrm{RMSEA}(90 \% \mathrm{CI})=0.07(0.04-$ $0.10)$ ), depressivity $(\mathrm{CFI}=1.0 \mathrm{RMSEA}(90 \% \mathrm{CI})=0.00(0.00-0.00))$ and impaired social and daily life $(\mathrm{CFI}=1.0, \operatorname{RMSEA}(90 \% \mathrm{CI})=0.08(0.07-0.10))$, CFI = 1.0 RMSEA $(90 \% \mathrm{CI})=0.00(0.00-0.00)$ (Reeve et al., 2007). Although, there is as statistically positive relationship in several studies between empowerment or empowerment-related outcomes and chronic diseases, there are many evidences proving existing bias in the corresponding item measurements. One of them is the improper evaluation of empowerment. The outcomes of "restricted in area" studies in this review may overestimate some interventions on patients population interventions such as researches with mental diseases. Moreover, the lack of enough of blinding RCTs is another important issue. According to limitations, the time lag between the gathering, the analysis of information and the publication of results, can be an important period of missing recent information. Last but not least, in some comparisons there was a weakness of follow-up, low level of evidences, nonsystematic data analysis and limited psychometric tests. In future research more generic measurements is needed to be added and it is demanded to expand the inclusion criteria in different languages, larger samples and longer time period.

\section{Methodological Cases}

Overall, the results of the systematic review presented a positive correlation between empowerment outcomes and chronic diseases there are many evidences proving existing bias in the corresponding item measurements. More specifically, empowerment cannot be measured, analyzed and evaluated properly due to the following factors: there is not enough evidences presenting self-esteem; considering ethical aspects empowerment effect on patients might be overestimated; empowerment can be also biased and unfounded since there is low social obedience to its standards. Furthermore, there is found an insufficient number of patients who undertake blind testing over a randomized clinical trial, and an extensive variety of combined studies on heterogeneous types of patients, research duration and empowerment pressure, which resulted on bi- 
ased results without possibility of a meta-analysis process.

\section{Conclusion}

In a conclusion, this systematic review highlighted the importance of a strong relationship development between the physician-clinical and the patient, based on long enriched and supportive conversations which targeted on patient empowerment. All types of chronic diseases (from syndromes, organ diseases to mental illnesses) are strongly dependent on a patient's empowerment and an increase of such empowerment through self-control and self-governing leads to the patient's health.

\section{Limitations}

In every systematic review like this one here, the first thing that must be examined is the search terms used for the gathering and the evaluation of the results. One of the most important limitations on the final paper results that must be considered, is the time lag between the gathering and the analysis of information and the publication of results. The problems here include the missing of updated information and recent study results about the examined topic of interest. In this particular study, the measures presented a positive correlation between empowerment and patient's health improvement, by relating empowerment with related terms as self-control, knowledge, attendance or decision making. We face important limitations when we seek for comparisons in other systematic studies which, due to limited provided portions of treatment, low level of evidences, nonsystematic data analysis and limited psychometric tests, provide false invalid inconsistent results incapable to be tested again.

\section{Future Research}

Up to today, there have been very important valid and reliable steps towards patient's empowerment. As a future goal we want our system to incorporate further generic measures which will be even more valid and reliable. This will be achieved with further studies open to different languages, operating in longer time and testing larger sample. The goal is a system able to distinguish and analyze different patient's results, in order to prove its effectiveness over patient's empowerment and prove a great contribution to other healthcare systems.

\section{References}

Ader, D. N. (2007). Developing the Patient-Reported Outcomes Measurement Information System (PROMIS). Medical Care, 45, S1-S2. http://dx.doi.org/10.1097/01.mlr.0000260537.45076.74

Alhani, F. (2002). Planning and Evaluation of Empowerment Based Family Model in Iron Deficiency Anemia. Doctorial Dissertation, Tarbiat Modares: Tarbiat Modares University.

Anderson, B. (2007). Collaborative Care and Motivational Interviewing: Improving Depression Outcomes through Patient Empowerment Interventions. American Journal of Managed Care, 13, S103-S106.

Anderson, R. (1995). Using the Empowerment Approach to Help Patients Change Behavior. In 
B. Anderson, \& R. Rubin (Eds.), Practical Psychology for Diabetes Clinicians (2nd ed., pp. 312). American Diabetes Association.

Anderson, R. M., \& Funnell, M. M. (2010). Using the Empowerment Approach to Help Patients Change Behaivior. In B. Anderson, \& R. Rubin (Eds.), Practical Psychology for Diabetes Clinicians (2nd ed., pp. 1-10). American Diabetes Association.

Andrew, N., \& Peterson, N. A. (2014). Empowerment Theory: Clarifying the Nature of Higher-Order Multidimensional Constructs. American Journal of Community Psychology, 53, 96108. http://dx.doi.org/10.1007/s10464-013-9624-0

Aujoulat, I., d'Hoore, W., \& Deccache, A. (2007). Patient Empowerment in Theory and Practice: Polysemy or Cacophony? Patient Education and Counseling, 66, 13-20. http://dx.doi.org/10.1016/j.pec.2006.09.008

Auquier, P., Simeoni, M. C., Sapin, C., Reine, G., Aghababian, V., Cramer, J., et al. (2013). Development and Validation of a Patient-Based Health-Related Quality of Life Questionnaire in Schizophrenia: The S-QoL. Schizophrenia Research, 63, 137-149. http://dx.doi.org/10.1016/S0920-9964(02)00355-9

Aymé, S., Kole, A., \& Groft, S. (2008). Empowerment of Patients: Lessons from the Rare Diseases Community. Lancet, 371, 2048-2051. http://dx.doi.org/10.1016/S0140-6736(08)60875-2

Beatty, P. C., \& Willis, G. B. (2007). Research Synthesis: The Practice of Cognitive Interviewing. Public Opinion Quarterly, 71, 287-311. http://dx.doi.org/10.1093/poq/nfm006

Blakeman, T., Chew-Graham, C., Reeves, D., Rogers, A., \& Bower, P. (2011). The Quality and Outcomes Framework and Self-Management Dialogue in Primary Care Consultations: A Qualitative Study. British Journal of General Practice, 61, 666-673. http://dx.doi.org/10.3399/bjgp11X601389

Bruegel, R. B. (1998). Patient Empowerment-A Trend That Matters. Journal of AHIMA, 69, 3033.

Bulsara, C., Styles, I., Ward, A. M., \& Bulsara, M. (2006). The Psychometrics of Developing the Patient Empowerment Scale. Journal of Psychosocial Oncology, 24, 1-16. http://dx.doi.org/10.1300/J077v24n02_01

Campbell, J., \& Schraiber, R. (1989) In Pursuit of Wellness: The Well-Being Project. Sacramento: California Department of Mental Health.

Campbell, J., Smith, P., Nissen, S., Bower, P., Elliott, M., \& Roland, M. (2009). The GP Patient Survey for Use in Primary Care in the National Health Service in the UK-Development and Psychometric Characteristics. BMC Family Practice, 10, 57.

http://dx.doi.org/10.1186/1471-2296-10-57

Coons, S. J., McGhan, W. F., Bootman, J. L., \& Larson, L. N. (1989). The Effect of Self-Care Information on Health-Related Attitudes and Beliefs of College Students. Journal of American College Health, 38, 121-124. http://dx.doi.org/10.1080/07448481.1989.9938429

Cooper, H., Booth, K., \& Gill, G. (2003). Using Combined Research Methods for Exploring Diabetes Patient Education. Patient Education and Counseling, 51, 45-52. http://dx.doi.org/10.1016/S0738-3991(02)00265-3

Corrigan, P. W., Giffort, D., Rashid, F., et al. (1999). Recovery as a Psychological Construct. Community Mental Health Journal, 35, 231-239. http://dx.doi.org/10.1023/A:1018741302682

Davison, B. J., \& Degner, L. F. (1997). Empowerment of Men Newly Diagnosed with Prostate Cancer. Cancer Nursing, 20, 187-196. http://dx.doi.org/10.1097/00002820-199706000-00004

Delavari, A. R., \& Mahdavihazaveh, M. (2005). Prevention and Controlling Diabetes (p. 45). Iran: Health Deputy, Disease Management Center, Ministry of Health of Iran. 
Department of Health (2004). Choosing Health: Making Healthy Choices Easier. London: Stationery Office.

Elzen, H., Slaets Joris, P. J., Snijders Tom, A. B., \& Steverink, N. (2007). Evaluation of the Chronic Disease Self-Management Program (CDSMP) among Chronically Ill Older People in the Netherlands. Social Science \& Medicine, 64, 1832-1841. http://dx.doi.org/10.1016/j.socscimed.2007.02.008

Esteghamati, A., Gouya, M. M., Abbasi, M., Delavari, A., Alikhani, S., Alaedini, F., Safaie, A., Forouzanfar, M., \& Gregg, E. W. (2008). Prevalence of Diabetes Mellitus and Impaired Fasting Glucose in the Adult Population of Iran: National Survey of Risk Factors for Non-Communicable Diseases of Iran. Diabetes Care, 31, 96-98. http://dx.doi.org/10.2337/dc07-0959

Fayers, P. M., \& Machin, D. (2007). Quality of Life: The Assessment, Analysis and Interpretation of Patient-Reported Outcomes (2nd ed.). Chichester: John Wiley \& Sons Ltd. http://dx.doi.org/10.1002/9780470024522

Ferketich, S. (1991). Focus on Psychometrics: Aspects of Itemanalysis. Research in Nursing \& Health, 14, 165-168. http://dx.doi.org/10.1002/nur.4770140211

Foster, G., Taylor, S. J. C., Eldridge, S. E., Ramsay, J., \& Griffiths, C. J. (2007). Self-Management Education Programmes by Lay Leaders for People with Chronic Conditions. Cochrane Database of Systematic Reviews, 2007, Article ID: CD005108.

Funnell, M. M., Nwankwo, R., Gillard, M. L., Anderson, R. M., \& Tang, T. S. (2005). Implementing an Empowerment-Based Diabetes Self-Management Education Program. Diabetes Educator, 31, 53-61. http://dx.doi.org/10.1177/0145721704273166

Funnell, M. M., \& Anderson, R. M. (2010). Empowerment and Self-Management of Diabetes. Clinical Diabetes, 22, 123-127. http://dx.doi.org/10.2337/diaclin.22.3.123

Gibson, C. H. (1991). A Concept Analysis of Empowerment. Journal of Advanced Nursing, 16, 354-361. http://dx.doi.org/10.1111/j.1365-2648.1991.tb01660.x

Gibson, C. H. (1995). The Process of Empowerment in Mothers of Chronically Ill Children. Journal of Advanced Nursing, 21, 1201-1210. http://dx.doi.org/10.1046/j.1365-2648.1995.21061201.x

Glaser, B. (1978). Theoretical Sensitivity. Mill Valley, CA: Sociology Press.

Glasgow, R., Wagner, E., Schaefer, J., Mahoney, L., Reid, R., \& Greene, S. (2005). Development and Validation of the Patient Assessment of Chronic Illness Care (PACIC). Medical Care, 43, 436-444. http://dx.doi.org/10.1097/01.mlr.0000160375.47920.8c

Gollings, E. K., \& Paxton, S. J. (2010). Comparison of Internet and Face-to-Face Delivery of a Group Body Image and Disordered Eating Intervention for Women: A Pilot Study. Eating Disorders, 14, 1-15. http://dx.doi.org/10.1080/10640260500403790

Gregorich, S. E. (2006). Do Self-Report Instruments Allow Meaningful Comparisons across Diverse Population Groups? Medical Care, 44, S78-S94. http://dx.doi.org/10.1097/01.mlr.0000245454.12228.8f

Hansson, L., \& Bjorkman, T. (2005). Empowerment in People with a Mental Illness: Reliability and Validity of the Swedish Version of an Empowerment Scale. Scandinavian Journal of Caring Sciences, 19, 32-38. http://dx.doi.org/10.1111/j.1471-6712.2004.00310.x

Harris, R., \& Veinot, T. (2004). The Empowerment Model and Using E-Health to Distribute Information. Vancouver: Action for Health, Simon Fraser University and the Vancouver Coastal Health Research Institute.

Haywood, K., Marshall, S., \& Fitzpatrick, R. (2006). Patient Participation in the Consultation Process: A Structured Review of Intervention Strategies. Patient Education and Counseling, 63, 
12-23. http://dx.doi.org/10.1016/j.pec.2005.10.005

Heinrich, E., Schaper, N. C., \& Vries, N. K. (2010). Self-Management Interventions for Type 2 Diabetes: A Systematic Review. European Diabetes Nursing, 7, 71-82.

http://dx.doi.org/10.1002/edn.160

Henwood, K., \& Pidgeon, N. (1992). Qualitative Research and Psychological Theorizing. British Journal of Psychology, 83, 97-111. http://dx.doi.org/10.1111/j.2044-8295.1992.tb02426.x

Hibbard, J., Collins, P., Mahoney, E., \& Baker, L. (2010). The Development and Testing of a Measure Assessing Clinician Beliefs about Patient Self-Management. Health Expect, 13, 65-72. http://dx.doi.org/10.1111/j.1369-7625.2009.00571.x

Homko, C. J., Santamore, W. P., Whiteman, V., Bower, M., Berger, P., Geifman-Holtzman, O., \& Bove, A. A. (2007). Use of an Internet-Based Telemedicine System to Manage Underserved Women with Gestational Diabetes Mellitus. Diabetes Technology \& Therapeutics, 9, 297-306. http://dx.doi.org/10.1089/dia.2006.0034

Howie, J., Heaney, D., \& Maxwell, M. (1997). Measuring Quality in General Practice (p. 75). Occasional Paper Series.

Huby, G., Brook, J. H., Thompson, A., \& Tierney, A. (2007). Capturing the Concealed: Interprofessional Practice and Older Patients' Participation in Decision-Making about Discharge after Acute Hospitalization. Journal of Interprofessional Care, 21, 55-67. http://dx.doi.org/10.1080/13561820601035020

Husted, G. R., Thorsteinsson, B., Esbensen, B. A., Hommel, E., \& Zoffmann, V. (2011). Improving Glycaemic Control and Life Skills in Adolescents with Type 1 Diabetes: A Randomised, Controlled Intervention Study Using the Guided Self-Determination-Young Method in Triads of Adolescents, Parents and Health Care Providers Integrated into Routine Paediatric Outpatient Clinics. BMC Pediatrics, 11, 55. http://dx.doi.org/10.1186/1471-2431-11-55

International Diabetes Federation (2011) Global IDF/ISPAD Guideline for Diabetes in Childhood and Adolescence. http://www.idf.org/diabetesatlas/5e/

Johansson, K., Lenino-Kilpi, H., Salantera, S., et al. (2003). Need for Change in Patient Education: A Finnish Survey from the Patient's Perspective. Patient Education and Counseling, 51, 239245. http://dx.doi.org/10.1016/S0738-3991(02)00223-9

Jones, K., Baggott, R., \& Allsop, J. (2004). Influencing the National Policy Process: The Role of Health Consumer Groups. Health Expect, 7, 18-28.

http://dx.doi.org/10.1111/j.1369-7625.2004.00238.x

Klima, C., Vonderheid, S., \& Norr, K. (2007). Conference Proceedings: Abstracts from Research Forums Presented at the ACNM 52nd Annual Meeting 2007. Journal of Midwifery \& Women's Health, 52, 531-535. http://dx.doi.org/10.1016/j.jmwh.2007.05.003

Lehman, A. F. (1983). The Well-Being of Chronic Mental Patients. Assessig Their Quality of Life. Archives of General Psychiatry, 40, 369-373. http://dx.doi.org/10.1001/archpsyc.1983.01790040023003

Lehman, A. F. (1988). A Quality of Life Interview for the Chronically Mentally Ill. Evaluation and Program Planning, 11, 51-62. http://dx.doi.org/10.1016/0149-7189(88)90033-X

Lewin, D., \& Piper, S. (2007). Patient Empowerment within a Coronary Care Unit: Insights for Health Professionals Drawn from a Patient Satisfaction Survey. Intensive and Critical Care Nursing, 23, 81-90. http://dx.doi.org/10.1016/j.iccn.2006.09.003

Liprie, M. L. (1993). Adolescents' Contributions to Family Decision Making. Marriage and Family Review, 18, 241-253. http://dx.doi.org/10.1300/J002v18n03_11

Little, P., Dorward, M., Warner, G., Moore, M., Stephens, K., Senior, J., \& Kendrick, T. (2004). Randomised Controlled Trial of Effect of Leaflets to Empower Patients in Consultations in 
Primary Care. BMJ, 328, 441. http://dx.doi.org/10.1136/bmj.37999.716157.44

Liu, M. Y., Tai, Y. K., Hung, W. W., Hsieh, M. C., \& Wang, R. H. (2010). Relationships between Emotional Distress, Empowerment Perception and Self-Care Behavior and Quality of Life in Patients with Type 2 Diabetes. The Journal of Nursing, 57, 49-60.

Lorig, K. R., Sobel, D. S., Ritter, P. L., Laurent, D., \& Hobbs, M. (2001). Effect of a Self-Management Program on Patients with Chronic Disease. Effective Clinical Practice, 4, 256-262.

Lorig, K. R., Laurent, D. D., Deyo, R. A., Marnell, M. E., Minor, M. A., \& Ritter, P. L. (2002). Can a Back Pain E-Mail Discussion Group Improve Health Status and Lower Health Care Costs? A Randomized Study. Archives of Internal Medicine, 162, 792-796. https://www.ncbi.nlm.nih.gov/pubmed/?term=Lorig\%2C+K.+R.\%2C+Laurent\%2C+D.+D.\%2 C+Deyo\%2C+R.+A.\%2C+Marnell\%2C+M.+E.\%2C+Minor\%2C+M.+A.\%2C+\%26+Ritter\%2C + P.+L.+(2002).+Can+a+Back+Pain + E-Mail+Discussion+Group+Improve + Health + Status + an d+Lower+Health+Care+Costs\%3F http://dx.doi.org/10.1001/archinte.162.7.792

Lorig, K. R., Ritter, P. L., Laurent, D. D., \& Plant, K. (2006). Internet-Based Chronic Disease Self-Management: A Randomized Trial. Medical Care, 44, 964-971. http://dx.doi.org/10.1097/01.mlr.0000233678.80203.c1

Lorig, K. R., Ritter, P. L., Laurent, D. D., \& Plant, K. (2008). The Internet-Based Arthritis SelfManagement Program: A One-Year Randomized Trial for Patients with Arthritis or Fibromyalgia. Arthritis \& Rheumatology, 59, 1009-1017. http://dx.doi.org/10.1002/art.23817

Machin, D., Campbell, M. J., Tan, S. B., \& Tan, S. H. (2011). Sample Sizes Tables for Clinical Studies. Hoboken, NJ: John Wiley \& Sons.

Man, D. W. K., Soong, W. Y. L., Tam, S. F., \& Hui-Chan, C. W. Y. (2006). A Randomized Clinical Trial Study on the Effectiveness of a Tele-Analogy-Based Problem-Solving Programme for People with Acquired Brain Injury (ABI). Neurorehabilitation, 21, 205-217.

Martin, P., Tamblyn, R., Ahmed, S., \& Tannenbaum, C. (2013). An Educational Intervention to Reduce the Use of Potentially Inappropriate Medications among Older Adults (EMPOWER Study): Protocol for a Cluster Randomized Trial. Trials, 14, 80.

http://dx.doi.org/10.1186/1745-6215-14-80

McCann, S., \& Weinman, J. (1996). Empowering the Patient in the Consultation: A Pilot Study. Patient Education and Counseling, 27, 227-234. http://dx.doi.org/10.1016/0738-3991(95)00830-6

Miles, M., \& Huberman, A. (2014). Qualitative Data Analysis (2nd ed.). London: Sage.

Miller, V. A., Reynolds, W. W., \& Nelson, R. M. (2008). Parent-Child Roles in Decision-Making about Medical Research. Ethics \& Behavior, 18, 161-181. http://dx.doi.org/10.1080/10508420802063947

Minet, L., Mohler, S., Vach, W., Wagner, L., \& Henriksen, J. (2010). Mediating the Effect of SelfCare Management Intervention in Type 2 Diabetes: A Meta-Analysis of 47 Randomized Controlled Trials. Patient Education and Counseling, 80, 29-41.

http://dx.doi.org/10.1016/j.pec.2009.09.033

Mishra, A., Sabaretnam, M., Chand, G., Agarwal, G., Agarwal, A., Verma, A. K., \& Mishra, S. K. (2013). Quality of Life (QoL) in Patients with Benign Thyroid Goiters (Pre- and Post-Thyroidectomy): A Prospective Study. World Journal of Surgery, 37, 2322-2329. http://dx.doi.org/10.1007/s00268-013-2133-3

Naberan, K., de La, R. C., Lamban, M., Gobartt, E., Martin, A., \& Miravitlles, M. (2006). Use of Spirometry in the Diagnosis and Treatment of Chronic Obstructive Pulmonary Disease in Primary Care. Archivos de Bronconeumologia, 42, 638-644. 
http://dx.doi.org/10.1016/S1579-2129(07)60006-8

Neuhauser, D. (2003). The Coming Third Health Care Revolution: Personal Empowerment. Quality Management in Health Care, 12, 171-184. http://dx.doi.org/10.1097/00019514-200307000-00007

Palloni, A., \& McEniry, M. (2007). Aging and Health Status of Elderly in Latin America and the Caribbean: Preliminary Findings. Journal of Cross-Cultural Gerontology, 22, 263-285. http://dx.doi.org/10.1007/s10823-006-9001-7

Rabe, K. F., Hurd, S., Anzueto, A., Barnes, P. J., Buist, S. A., Calverley, P., Fukuchi, Y., Jenkins, C., Rodriguez-Roisin, R., Van-Wel, C., \& Zielinski, J. (2007). Global Strategy for the Diagnosis, Management, and Prevention of Chronic Obstructive Pulmonary Disease: GOLD Executive Summary. American Journal of Respiratory and Critical Care Medicine, 176, 532-555. http://dx.doi.org/10.1164/rccm.200703-456SO

Reeve, B. B., Hays, R. D., Bjorner, J. B., Cook, K. F., Crane, P. K., Teresi, J. A., Thissen, D., Revicki, D. A., Weiss, D. J., Hambleton, R. K., Liu, H., Gershon, R., Reise, S. P., Lai, J. S., \& Cella, D. (2007). Psychometric Evaluation and Calibration of Health-Related Quality of Life Item Banks: Plans for the Patient-Reported Outcomes Measurement Information System (PROMIS). Medical Care, 45, S22-S31. http://dx.doi.org/10.1097/01.mlr.0000250483.85507.04

Roberts, K. J. (1999). Patient Empowerment in the United States: A Critical Commentary. Health Expect, 2, 82-92. http://dx.doi.org/10.1046/j.1369-6513.1999.00048.x

Segal, L. (1998). The Importance of Patient Empowerment in Health System Reform. Health Policy, 44, 31-34. http://dx.doi.org/10.1016/S0168-8510(98)00007-4

Segal, S., Silverman, C., \& Temkin, T. (1995). Measuring Empowerment in Client-Run Self-Help Agencies. Community Mental Health Journal, 31, 215-227.

http://dx.doi.org/10.1007/BF02188748

Sjöblad, S. (2008). Barn- och ungdomsdiabetes. Lund: Studentlitteratur, 2. [uppdaterade och utvidgade] uppl. edn. BMC Pediatricsics, 13, 212.

Small, N., Bower, P., Chew-Graham, C. A., Whalley, D., \& Protheroe, J. (2013). Patient Empowerment in Long-Term Conditions: Development and Preliminary Testing of a New Measure. BMC Health Services Research, 13, 263. http://dx.doi.org/10.1186/1472-6963-13-263

Sumie, Y., \& Kunifumi, S. (2007). Application of Empowerment Scale to Patients with Schizophrenia: Japanese Experience. Psychiatry and Clinical Neuroscience, 61, 594-601. http://dx.doi.org/10.1111/j.1440-1819.2007.01723.x

SWEDIABKIDS (2011) Nationellt register för barn- och ungdomsdiabetes, Arsrapport 2011. Ars Resultat.

Tomes, N. (2007). Patient Empowerment and the Dilemmas of Late-Modern Medicalisation. Lancet, 369, 698-700. http://dx.doi.org/10.1016/S0140-6736(07)60318-3

Tsay, S.-L., \& Hung, L.-O. (2004). Empowerment of Patients with End-Stage Renal Disease-A Randomized Controlled Trial. International Journal of Nursing Studies, 41, 59-65. http://dx.doi.org/10.1016/S0020-7489(03)00095-6

Uner, S., \& Turan, S. (2010). The Constructvalidity and Reliability of the Turkish Version of Spreitzer's Psychological Empowerment Scale. BMC Public Health, 10, 117. http://dx.doi.org/10.1186/1471-2458-10-117

Viklund, G., Ortqvist, E., \& Wikblad, K. (2007). Assessment of an Empowerment Education Programme. A Randomized Study in Teenagers with Diabetes. Diabetic Medicine, 24, 550-556. http://dx.doi.org/10.1111/j.1464-5491.2007.02114.x

Wahlin, I., Ek, A. C., \& Idvall, E. (2006). Patient Empowerment in Intensive Care: An Interview Study. Intensive and Critical Care Nursing, 22, 370-377. 
http://dx.doi.org/10.1016/j.iccn.2006.05.003

Watt, T., Hegedüs, L., Groenvold, M., Bjorner, J. B., Rasmussen, A. K., Bonnema, S. J., \& FeldtRasmussen, U. (2010). Validity and Reliability of the Novel Thyroid-Specific Quality of Life Questionnaire, ThyPRO. European Journal of Endocrinology, 162, 161-167. http://dx.doi.org/10.1530/EJE-09-0521

WHO Study Group (1985). Diabetes Mellitus: Report of a WHO Study Group. World Health Organization Technical Report Series, 727, 1-113.

Wong, A. L., Harker, J. O., Lau, V. P., Shatzel, S., \& Port, L. H. (2004). Spanish Arthritis Empowerment Program: A Dissemination and Effectiveness Study. Arthritis \& Rheumatology, 51, 332-336. http://dx.doi.org/10.1002/art.20395

Zhang, Y., Su, H., Li, D., Wanq, R., Zhanq, R., \& Xiu, Y. (2011). Preferences and Perceived Involvement in Treatment Decision Making among Chinese Patients with Chronic Hepatitis. Medical Decision Making, 31, 245-253. http://dx.doi.org/10.1177/0272989X10375990

Zimmerman, M. A. (1995). Psychological Empowerment: Issues and Illustrations. American Journal of Community Psychology, 23, 581-599. http://dx.doi.org/10.1007/BF02506983

Zoffmann, V., \& Kirkevold, M. (2012). Realizing Empowerment in Difficult Diabetes Care: A Guided Self-Determination Intervention. Qualitative Health Research, 22, 103-118. http://dx.doi.org/10.1177/1049732311420735

Zutz, A., Ignaszewski, A., Bates, J., \& Lear, S. A. (2007). Utilization of the Internet to Deliver Cardiac Rehabilitation at a Distance: A Pilot Study. Telemedicine and E-Health, 13, 323-330. http://dx.doi.org/10.1089/tmj.2006.0051

Submit or recommend next manuscript to SCIRP and we will provide best service for you:

Accepting pre-submission inquiries through Email, Facebook, LinkedIn, Twitter, etc. A wide selection of journals (inclusive of 9 subjects, more than 200 journals)

Providing 24-hour high-quality service

User-friendly online submission system

Fair and swift peer-review system

Efficient typesetting and proofreading procedure

Display of the result of downloads and visits, as well as the number of cited articles

Maximum dissemination of your research work

Submit your manuscript at: http://papersubmission.scirp.org/

Or contact psych@scirp.org 